\title{
Optimization of physicochemical parameters of a multilayered polyelectrolyte film deposition with Love wave and AFM for bacteria based detection of heavy metals
}

\author{
I.Gammoudi $^{*^{1,2,3}}$, C.Grauby-Heywang ${ }^{2}$, F. Moroté ${ }^{2}$,V. Raimbault ${ }^{1}$, A.Othmane ${ }^{4}$, R.Kalfat ${ }^{3}$, D.Moynet ${ }^{5}$, \\ D.Rebière ${ }^{1}$, C.Dejous ${ }^{1}$, T.Cohen-Bouhacina ${ }^{2}$ \\ ${ }^{1}$ Univ. Bordeaux, Laboratoire IMS, CNRS UMR 5218, 351 crs Libération, 33405 Talence, France \\ ${ }^{2}$ Univ. Bordeaux, LOMA, CNRS UMR 5798, 351 crs Libération, 33405 Talence, France \\ ${ }^{3}$ Institut National de Recherche et d'Analyse Physico-chimique, BioTechpole, Sidi-Thabet, Tunisia \\ ${ }^{4}$ Laboratoire de Biophysique, Faculté de Médecine, Monastir 5019, Tunisie \\ ${ }^{5}$ Univ. Bordeaux, Laboratoire d'Immunologie, 146 rue Léo Saignat, Bât.1B, 33076 Bordeaux, France \\ ibtissemgammoudi@yahoo.fr
}

\begin{abstract}
:
A biosensor based on Escherichia coli Bacteria for determination of heavy metal ions with an acoustic Love wave device and Polydimethylsiloxane (PDMS) microfluidic network has been previously developed, that provides fast detection of toxic chemical compounds. Bacteria were immobilized on the transducer coated with self-assembled molecular multilayers of polyelectrolytes. In this study, we emphasize Love wave and AFM-based complementary characterization methods, which allowed an optimization of some physicochemical parameters of polyelectrolyte solutions, such as $\mathrm{pH}$, ionic strength or molecular weight, in order to increase the immobilization of bacteria as well as the sensor lifetime. For instance, an increase density of bacteria was observed when using alternative $\mathrm{pH}$ of 9 for cationic solution.
\end{abstract}

Key words: Escherichia coli, heavy metal, polyelectrolytes, Love wave, AFM, microfluidic PDMS cell

\section{Introduction}

Heavy metal wastewater exists in various industries, such as metal finishing, electroplating, plastics, pigments and mining, which threatens to the environment and human lives severely [1].

Therefore, research on ecological risk assessment of heavy metals in the polluted water gets more and more attention [2]. Heavy metal detection in aqueous medium can be achieved by conventional methods, including mass spectrometry (ICPMS), atomic absorption (AA), spectroscopy, and inductively coupled plasma (ICP), but they are quite expensive and cannot be used for continuous measurements in situ. Sensor presents a simple, sensitive and fast alternative method that would be of great significance for wide scale monitoring and environmental analysis.

Love waves are acoustic modes that propagate in a layered structure consisting of a substrate and a thin wave-guiding layer on top. The wave confinment at the near surface within the top layer leads to an increased sensitivity to mechanical changes at the surface. Mass- loading effect and generation of Love waves are well described in literature [3]. Due to the high sensitivity and the transverse wave type (shear horizontally polarized surface guided waves), sensors based on Love waves appear promising for (bio) chemical applications in gases and liquids [4]. The interaction of the acoustic wave with the surrounding medium causes changes in the velocity and amplitude of the wave indicated by a variation of the resonance frequency of the delay-line controlled oscillator.

In the objective of a miniaturized system and a continuous detection, microfluidic technology presents a key feature for biological and biochemical sensor aiming environmental applications. For example, chemically patterned microchannels have been used in miniaturized biological assays and biosensors [5], in the formation of biomimetic 3D structures, and the promotion or reduction of cell adhesion in specific regions of microchannels. Polydimethylsiloxane (PDMS) is widely used as materials for microfluidic chips, in particular with biological aims. Among advantages, it presents 
interesting properties such as biocompatibility and ease of prototyping.

In this study, we adopted a related approach for the development and initial testing of a PDMS microfluidic device for the miniaturization of a heavy metals bacteria-based sensor.

\section{1- Materials and methods}

\section{Love wave sensor}

The microsensor is based on a piezoelectric effect to create and propagate an acoustic wave. An AT-cut quartz substrate with interdigitated electrodes (IDTs) parallel to the crystallographic $X$-axis (Euler Angles: $0^{\circ}$; $\left.121.5^{\circ}, 90^{\circ}\right)$, permits to generate pure shear horizontal $(\mathrm{SH})$ waves, and so to work with an adjacent liquid medium. A $4 \mu \mathrm{m} \mathrm{SiO}_{2}$ guiding layer was added in order to trap acoustic energy and to generate guided SH-SAW or Love wave [6].

\section{PDMS microfluidic network}

The combination of a PDMS chip with the acoustic device (Fig.1) not only gathered the advantages of each part, but also allowed protection of the electrodes (air cavities upon IDTs) as well as enhancement of the control of the flow at the near surface of the sensor (analysis chambers). A removable assembly of the two chips by pressure against each other facilitated access to the main surface, for agressive chemical modification, or cleaning and thus, reusability.

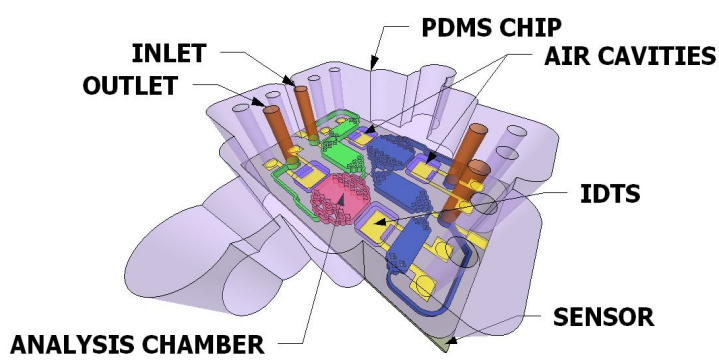

Fig. 1 PDMS cell with microfluidic network [9]

Soft-lithography is commonly used for fabricating microfluidic devices from PDMS because the prototyping process is simple, fast and inexpensive.

In this work, the microfluidic chips with integrated micro channels for a dual delay-line (Fig.2) were realized using this method, together with micromachining for external 3D shapes. These PDMS chips were microfabricated by means of silicon wafer with spin-coating of a SU-8 resin at $2000 \mathrm{rpm}$ to obtain a negative mold with membranes 200 $\mu \mathrm{m}$ thick as polymer template. The PDMS chip was then formed from a liquid PDMS oligomer and a cross-linking agent (weight ratio of 9:1).
Both components were mixed and put with a syringe pump at flow equal to $1 \mathrm{ml} / \mathrm{min}$ to obtain a good homogenization of PDMS in the mold. After that, PDMS was cured for $20 \mathrm{~min}$ at $95^{\circ} \mathrm{C}$ and the resulting chip with the microfluidic network pattern was peeled off from the mold. Using a home-made test cell maintaining the PDMS chip with proper alignment and removable sealing on the Love wave device, the fluid sample was pulled through the acoustic path with programmable syringe pumps. Further details can be found in [7].
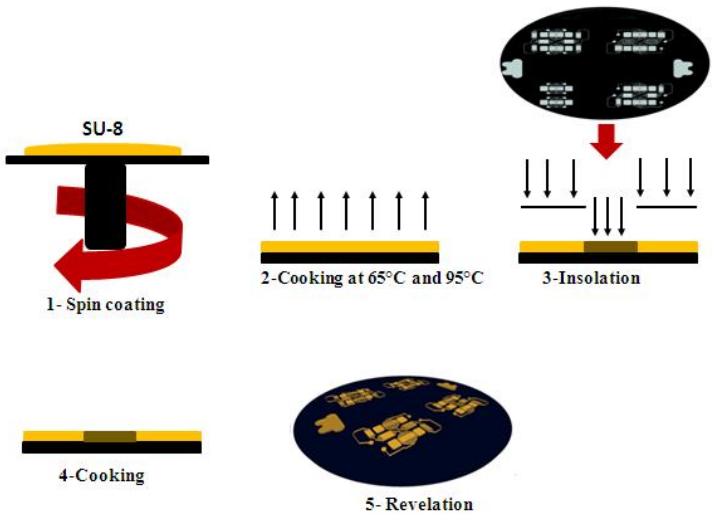

Fig. 2 Soft-lithography method for SU-8 mold with microfluidic patterns

\section{AFM experiments}

Atomic Force Microscopy (AFM) is a powerful imaging tool that mechanically probes a surface. This technique gives several informations such as topography from the atomic scale to hundred of nanometers, mechanical properties and interaction forces at different levels, in air or liquid [8].

AFM NSI platform equipped with the bioscope II (Veeco Instruments) was used. The tip used for these experiments was of tapping mode, in $\mathrm{Si}_{3} \mathrm{~N}_{4}$ with stiffnesses of the order of $50 \mathrm{~N}^{-\mathrm{M}^{-1}}$.

The scan rate was at $0.5 \mathrm{~Hz}$ for all the data presented in this paper.

\section{Chemical and biological}

Two types of polyelectrolytes (PE) were used: polyallylamine hydrochloride (PAH), a cationic type with two molecular weights (MW) of 56,000 and 15,000, and polysodium 4-styrenesulfonate (PSS), an anionic type having molecular weight of about 70,000 . PE $(5 \mathrm{mg} / \mathrm{ml})$ were prepared in TBS (Tris Buffered Saline) solution (0.15M). E. coli bacteria, gift from DGA (France), were used at a concentration corresponding to an optical density, measured at $600 \mathrm{~nm}$, equal to 0.6 . The stock solutions $(1 \mathrm{~g} / \mathrm{l})$ of Cadmium $\left(\mathrm{Cd}^{2+}\right)$ and Mercury $\left(\mathrm{Hg}^{2+}\right)$ were prepared from $\mathrm{Cd}\left(\mathrm{NO}_{3}\right)_{2} \cdot\left(\mathrm{H}_{2} \mathrm{O}\right)_{4}$ and $\mathrm{Hg}\left(\mathrm{NO}_{3}\right)_{2} \cdot\left(\mathrm{H}_{2} \mathrm{O}\right)$ in TBS. All products purchased from Sigma Aldrich. 


\section{1- Results and discussion}

\section{Effect of physicochemical parameters on polyelectrolyte film self-assembly}

PE multilayer formation was realized by the alternative flow of $\mathrm{PAH}$ and PSS solutions in the microfluidic system with a flow rate equal to $20 \mu \mathrm{l} / \mathrm{min}$ [9], and intermediate rinsing steps (0.15 M TBS). The influence of molecular weight (MW) can be readily observed on fig.3a, with steady-state frequency shifts increased when using $\mathrm{PAH}$ with higher $\mathrm{MW}$ (both $\mathrm{PE}$ solution at $\mathrm{pH}=7.2$ ). On Fig. $3 \mathrm{~b}$ shows the influence of $\mathrm{pH}$ parameter. The cumulative steady-state frequency shift is significantly increased of about $40 \mathrm{kHz}$ for three bilayers when the solution of PAH/PSS is basic $\left(\mathrm{pH}_{\mathrm{PAH}}=9\right) /$ acid $\left(\mathrm{pH}_{\mathrm{PSS}}=4\right)$ respectively, instead of neutral. Indeed, at $\mathrm{pH}=9$, the $\mathrm{SiO}_{2}$ surface is



completely negatively charged which increases the interaction between the surface and a first layer of $\mathrm{PAH}$, also, this combination of $\mathrm{pH}$ values, avoids the steric hindrance, allowing the two polyelectrolytes to interact with each other more easily.

Thus, we have shown that the PE adsorption depends on the $\mathrm{pH}$ of the $\mathrm{PE}$ immersion solution: $\mathrm{pH}$ controls the degree of ionization of the PE, and therefore, its conformation and degree of ionic cross-linking, so the film thickness. From a physico-chemical point of view, considering both $\mathrm{PE}$ and electrostatic interactions involved in this process of selfassembly, the main effect should be due to the $\mathrm{pH}$ of $\mathrm{PAH}$ solution; undergoing experiments are conducted in order to verify this hypothesis.

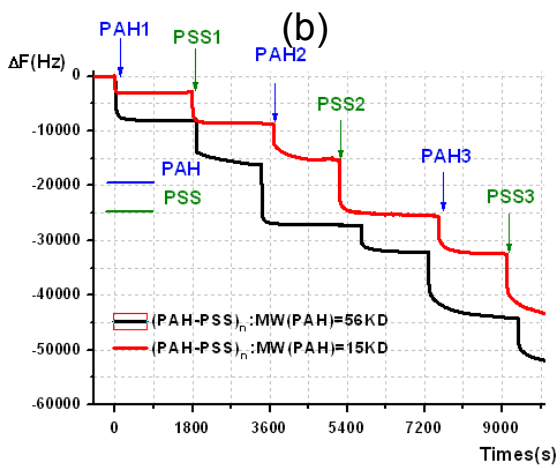

Fig.3 Influence of polyelectrolyte parameters, a) molecular weight of $P A H$ (@pH=7.2); b) $p H$ (@MW $W_{P A H}=56$ kDa; red curve: $p H=7.2$, black curve: $\left.p H_{P A H}=9, p H_{P S S}=4\right)$.

A systematic study of these samples was also achieved with AFM, using topographical analysis in tapping mode in air. It could be observed that PE covers completely the surface sample while forming a homogeneous distribution of aggregates whose size is changing with $\mathrm{pH}$ (the mean roughness measured on an area of $1 \mu \mathrm{m}^{2}$ is about $4 \mathrm{~nm}$ for $\mathrm{pH}=7.2$ and $5.4 \mathrm{~nm}$ for $\mathrm{pH}_{\mathrm{PAH}}=9$ ).

\section{Influence of $\mathrm{pH}$ on bacteria immobilization}

In this work, up to three complete bilayers and a half were deposited: (PAH-PSS) $)_{3}-\mathrm{PAH}$. For comparison, bacteria were deposited on three different surfaces, a surface ending with a layer of PSS (-) (result not shown), and surfaces of (PAH-PSS $)_{3}-\mathrm{PAH}$ with a $\mathrm{pH}$ of 7.2 or with a $\mathrm{pH}$ of $\mathrm{PAH}$ solution equal to 9 in order to estimate the influence of the electrical charge and of $\mathrm{pH}$. Bacteria were immobilized by physical adsorption on these different surfaces

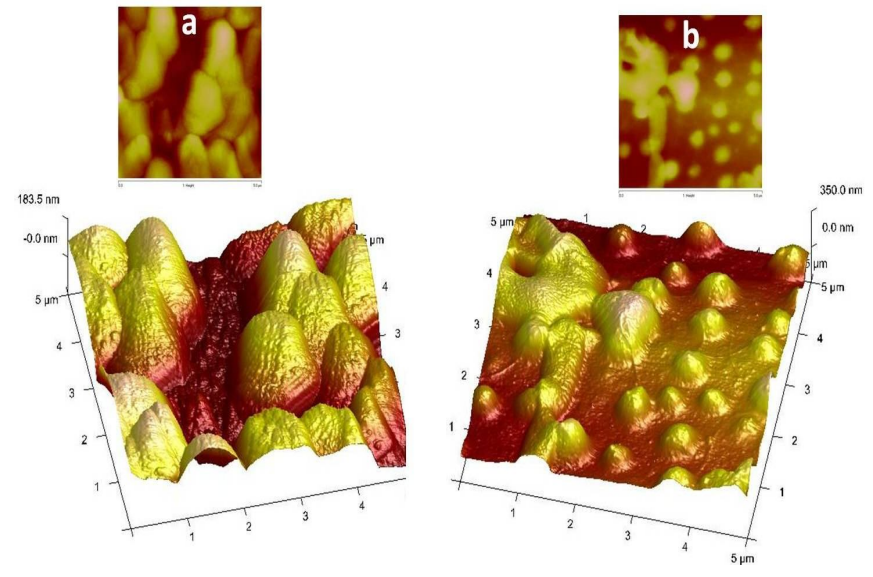

Fig. 4: 3D-Topographic image AFM for two surfaces: a) $\mathrm{SiO}_{2}-(\mathrm{PAH}-\mathrm{PSS})_{3}-\mathrm{PAH}-\mathrm{E}$.coli $\left(\mathrm{pH}_{\mathrm{PAH}}=9\right.$, $\left.\mathrm{pH}_{P S S}=4\right)$ and b) $\mathrm{SiO}_{2}-(P A H-P S S)_{3}-P A H-E$.coli $(\mathrm{pH}=7,2)$.

We have noted that the amount of immobilized bacteria is increased on a positively charged surface, as it could be expected, since the cell wall of $E$. coli has an overall negative charge. Secondly the $\mathrm{pH}$ of solutions has also an important role, as it can be seen on the 
topographic images on Fig.4. we can note on fig $4 \mathrm{~b}$ on which bacteria can be distinguished from each other, that their immobilization is in two directions, both vertically and horizontally, as shown in Fig.4b, with numerous bacteria immobilized with( $\mathrm{pH} \mathrm{PAH}_{\mathrm{P}}=9$, Fig 4-a) form a film more homogenous than $(\mathrm{pH} \mathrm{PAH}=7,2$, Fig4-b). This influence of the $\mathrm{pH}$ can be explained considering mechanisms of interactions and of immobilization involved. Indeed, during a first step, bacteria form relatively weak and reversible van der Waals, electrostatic and hydrophobic bonds with the surface. These interactions are $\mathrm{pH}$ dependant. These resulting physical bond are generally considered to be easily removed during this step by rinsing, although there have been documented instances where shear stress enhanced binding (e.g., adhesion on pili or fimbriae). This biological binding corresponds to a second step from which bacteria are brought within nanometers of the surface.

\section{Conclusion}

We have shown a way of optimization of physico-chemical parameters involved in the deposition of a sensitive film coating for a whole-cell based microsensor, using combined characterization with in-situ and real-time measurements during coating with (Love wave - microfluidic chip) device and AFM measurements. It was applied to the immobilization of E.coli bacteria on polyelectrolytes (PAH and PSS) self-assembled multilayers and it was found that a higher molecular weight and a basic $\mathrm{pH}$ of $\mathrm{PAH}$ solution could improve some characteristics of the biosensitive film so obtained. Some explanations of physico-chemical interactions involved in the formation of the film have been proposed.

Works on heavy metal detection with optimized surface are outstanding, and will be compared with results found previously [8] with a usual surface $(\mathrm{pH}=7,2)$.

\section{Acknowledgements}

The overall project on the bacterial-based Love wave device for heavy metals detection is conducted through the CMCU project $\mathrm{n}^{\circ}$ 10G1103. PDMS chips were designed in the frame of Ph.D. works of H. Tarbague, through the ANR project BIOALERT. The authors also want to thank M. Benoît from LAAS-CNRS (Toulouse France) for processing of piezoelectric delay-lines through the national technical realization network RTB.

\section{References}

[1] T.A. Kurniawan, G.Y.S. Chan, W. Lo, S. Babel, Comparisons of low-cost adsorbents for treating wastewaters laden with heavy metals, Science of the Total Environment, 366 (2006) 409-426; doi : S004896970500728

[2] H.C. Cao, Z.Q. Luan, J.D. Wang, X.L. Zhang, Potential ecological risk of cadmium, lead and arsenic in agricultural black soil in Jilin Province, China Stoch Environ Res Risk Assess, 23(2009) 57-64; doi: s00477-007-0195-1

[3] M.I. Newton, G. McHale, F. Martin, Experimental study of Love wave devices with thick guiding layers, Sensors and Actuators A: Physical, 109 (2004) 180-185; doi : S0924-4247(03)00676-9

[4] N. Moll, E. Pascal, D.H. Dinh, J.P. Pillot, B. Bennetau, D. Rebière, D. Moynet, Y. Mas, D. Mossalayi, J. Pistré, C. Dejous, A Love wave immunosensor for whole E.coli bacteria detection using an innovative two-step immobilization approach, Biosensors and Bioelectronics, 22 (2007) 2145-2150; doi : S0956566306004805

[5] N.Y. Lee, J.R. Lim, Y.S. Kim, Biosensors and Bioelectronics 21 (2006) 2188-93; doi :

[6] F.Razan, C. Zimmermann, D. Rebière, C. Dejous, J. Pistré, M. Destarac, B. Pavageau, Radio frequency thin film characterization with polymer-coated Love-wave sensor, Sensors and Actuators, 108 (2005) 917-924; doi : S0925400505000468

[7] H. Tarbague, J.-L. Lachaud, S. Destor, L. Vellutini, J.-P. Pillot, B. Bennetau, E. Pascal, D. Moynet, D. Mossalayi, D. Rebière, and C. Dejous, Journal of Integrated Circuits and Systems, 2, $125-133$ (2010); doi : 10.1149/1.3183735

[8] A. Simon, T. Cohen-Bouhacina, M. C. Porte, J. P. Aime, J. Amédée, R. Bareille and C. Baquey Characterization of Dynamic Cellular Adhesion of Osteoblasts Using Atomic Force Microscopy" Cytometry Part A 54A, 36-47 (2003) doi: 10.1002/cyto.a.10052

[9] I. Gammoudi, H. Tarbague, J.L. Lachaud, S. Destor, A. Othmane, D. Moynet, R. Kalfat, D. Rebière, C. Dejous, Love wave bacterial biosensors and microfluidic network for detection of heavy metal toxicity, Sensor Letters, 9, 816819 (2011); doi: 10.1166/sl.2011.1621

[10] M. Mouse, D. Duck, The Beagle Boys for President, Journal of Applied Nonsense 13, 123134 (2011); doi: 10.1234/s10000 